\title{
Poverty Results In Madness: A Testimony from the Past
}

\author{
Maria Cristina Turola ${ }^{1 *}$, Lodovico Umberto Tucci² ${ }^{2}$ Emanuela Carantoni ${ }^{3}$, Fiora \\ Gaspari $^{4}$ and Luigi Armiato ${ }^{5}$ \\ ${ }^{1}$ Psychiatrist, "Club Integriamoci" Association, Ferrara, Italy \\ ${ }^{2}$ Nurse, "Club Integriamoci" Association, Ferrara, Italy \\ ${ }^{3}$ Medical and Pharmaceutical Biotechnology, "Club Integriamoci" Association, Ferrara, Italy \\ ${ }^{4}$ Classic letters, Archivist, Venice Archive - San Servolo Servizi-San Servolo Island, Venice, Italy \\ ${ }^{5}$ Phylosophy, Archivist, Venice Archive - San Servolo Servizi- San Servolo Island, Venice, Italy
}

Received: May 21, 2015; Accepted: September 10, 2015; Published: September 20, 2015

*Corresponding author: Maria Cristina Turola, psychiatrist, "Club Integriamoci" Association, Ferrara, Italy. Viale Cavour 18344121 Ferrara (Italy), Tel: 0039349 5627510; Fax: 0039 1786053132; E-Mail: chiartur@gmail.com

\begin{abstract}
The Archives preserve documents of the past, providing valuable information on the characteristics of a population affected by a disease and the "natural" course of diseases.

Aims: To study a population hospitalized in an Italian Psychiatric Hospital in the nineteenth century, coming from a specific geographic area: the province of Rovigo, named Polesine.

Study design and Methodology: A systematic retrospective chart review study included all the cases ( $\mathrm{N}=940)$, coming from Polesine, hospitalized in the Venice Psychiatric Hospitals in the period 18661899. All data reported in the Archive's folders were collected and categorized as: age during the admission, gender, marital status, number of children, level of education, presence of poverty, date and diagnosis of admission, hospitalization length, date of discharge, number of deaths and diagnosis of death. The research carried out both a descriptive study and an analytic study, looking for bivariate relationships; correlation coefficient and tetrachoric correlations were applied.
\end{abstract}

Results: Alienation was frequent: 1/197 inhabitants were admitted into the Venice Psychiatric Hospital. The $43.4 \%$ of them died during their stay in the hospital. Among the survivors, healing and clinical improvement were the prevalent outcomes. Although pellagra was the most represented disease, malnutrition and tuberculosis were very common.

Gender differences appear in the data: women were more affected by pellagra $(57.6 \%$ versus $47.7 \%)$ and died at a higher percentage than men $(48.3 \%$ versus $38.7 \%)$.

Conclusion: Poverty, widespread both in all the hospitalized cases (99.47\%) and in the Polesine population, appears in this study as the main factor leading to madness.

Keywords: Madness; Mental Diseases; Archives; Poverty; Pellagra; Chart Review

\section{Introduction}

The Archives preserve documents of the past, mines of interesting data, useful for research; their function is not to collect dust, while occupying forgotten spaces, but to be opened, consulted, reviewed using current knowledge [1]. While historical research systematically refers to archive documents, in the health field we rarely deal with the past, perhaps considering it exceeded by subsequent discoveries and developments in the history of medicine.

However, to review historical cases using current knowledge can provide valuable information on the characteristics of a population affected by a disease, the "natural" course of this disease in the absence of effective treatments, analogies or differences with current illnesses and treatment choices and health policies. In psychiatry, these considerations are particularly suitable for the difficulty in identifying etiology and pathogenesis of diseases, the variability of nosography, the strong connection between symptoms and cultural factors and the segregation that always characterizes this field.

Can this model of research have some utility for the present time? In our opinion, it can, because: the history of populations tends to repeat itself in cycles [2]; progress is not a one-way phenomenon and economic crises can undermine decades of good practice; in all societies there are groups of people who do not have access to health care; finally, because most of the world population currently lives in conditions similar to those of the populations of developed countries in the past.

This study concerns a specific geographical area, named Polesine, corresponding to the Province of Rovigo, Veneto Region, Italy, in the period between its annexation to Italy, on November 1866, and the end of the nineteenth century. It studies the population coming from Polesine that where admitted into the Psychiatric Hospitals in Venice. The research aims to study 
madness in that time, taking into accounts the characteristics of people affected the incidence of the various pathologies, the diagnoses, the causes of death, courses, outcomes and the correlations among the different parameters.

\section{Background and Caseload}

Polesine is a completely flat area sandwiched between two rivers, the Adige and the Po, and the Adriatic Sea. For many centuries, Polesine was a marginal land between the Republic of Venice and the Papal States. In 1815, the Wien Congress established the current borders, creating the Rovigo Province. In 1866, together with all the Veneto Region, it was annexed to Italy; since then, the borders have remained unchanged. The Province was initially divided into 66 municipalities and now these are 50: only eight had over 5000 inhabitants and only 5 reached 10000 inhabitants.

In 1871, Polesine had a population of 202232 inhabitants, with a male / female ratio of 1.02/1. In 1901, there were 222 067 inhabitants. Almost the entire population was illiterate and worked as peasants, in the widespread cultivations of maize. There were few landowners while all the others were peasants who worked only during planting or harvest season, or tenants of small farms that could only keep a small part of the harvest for themselves. Poverty dominated, people could barely survive in conditions of malnutrition. Malaria, pellagra and scurvy were endemic; due to the deplorable hygienic conditions, epidemics of typhoid and cholera periodically decimated the population and tuberculosis affected mainly young people.

The poor immigrated massively to the Americas, fleeing hunger and looking for a better life [3]. In that period the disastrous flood of the Adige (September 1882) occurred, which flooded one-half of Polesine, bringing famine: subsequent years (1884-86) were characterized by widespread and prolonged peasant revolts.

The medical knowledge at the time, seen from the current perspective, was very poor; psychiatry was in its infancy, psychology and psychoanalysis were yet to be born and the concept of rehabilitation was non-existent. Psychiatric therapies were often based on the ancient theory of humor, of heat and cold; almost all diseases were treated with purgatives, bloodletting or applying leeches or, at best, with tonics, milk, wine and coffee. There were no active drugs for infections and hygiene was very poor; any infection, inflammation or trauma had high chances to lead to death.

Municipality doctors identified psychiatric patients, who were also defined as "alienated" and wrote up a standardized schedule, relating socio-demographic and clinical information. The Municipality required hospitalization in the mental hospital and a Provincial Commission examined the documentation, approving or rejecting and sometimes proposing alternative solutions, such as safekeeping at home or hospitalization in a general hospital. When the hospitalization was approved, the alienated were sent primarily to the Regional Asylum of Venice, where the Rovigo Province had 148 beds available, 74 for men and 74 for women. The documentation kept at the Venice Asylum Archive consists of almost all the mental hospital admissions of cases coming from Polesine at that time.

\section{The Archive}

The history of Venice Asylum [4,5,6,7] begins in 1725 with the admission of the first alienated in the Hospital of San Servolo Island, directed by the religious congregation of St. John of God, "Fatebenefratelli". After more than two centuries it ends, in August 1978, when the Asylum was closed, following the Basaglia law n. 180/78, which reformed the entire psychiatric care system.

At the closing of the Psychiatric Hospital, the Province of Venice inherited a rich and unique archival heritage, for the conservation of which instituted, in 1979, the San Servolo IRSESC Foundation (Institute for Research and the Study on Social and Cultural Exclusion) based on the Island [8]. The purpose of the Foundation was to promote research and studies on all forms of disadvantage and social and cultural marginalization, with particular attention to the exploitation of the hospital archival heritage, which guaranteed the preservation, protection and fruition. The Archive retains clinical and administrative documents from 1713 to the end of the Twentieth Century, regarding the two Psychiatric Hospitals of Venice [9].

The relevant documentation is undoubtedly represented by the series of medical records (Figure 1) which together amount to almost 50,000, a very interesting photographic collection, made up of portraits of patients inserted in many medical records (Figure 2), and several albums of portraits and locations.

In addition to the computerized indices of names of all patients, the complex is equipped with comprehensive analytical inventories, which were completed in 2006.

The completeness of the documentation, the careful preservation and inventory are a rare phenomenon, precious because it allows researchers to design retrospective studies on numerous samples with reliable data.

\section{Medical record - male (1889)}
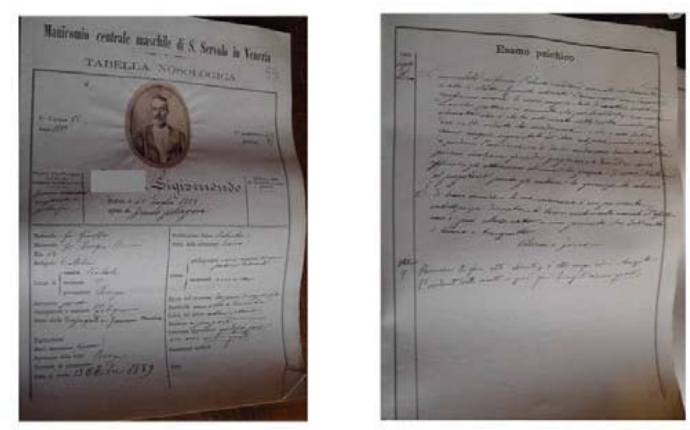

Figure 1: Example of a clinical record (Folder 29). The patient was admitted and discharged in 1889. 


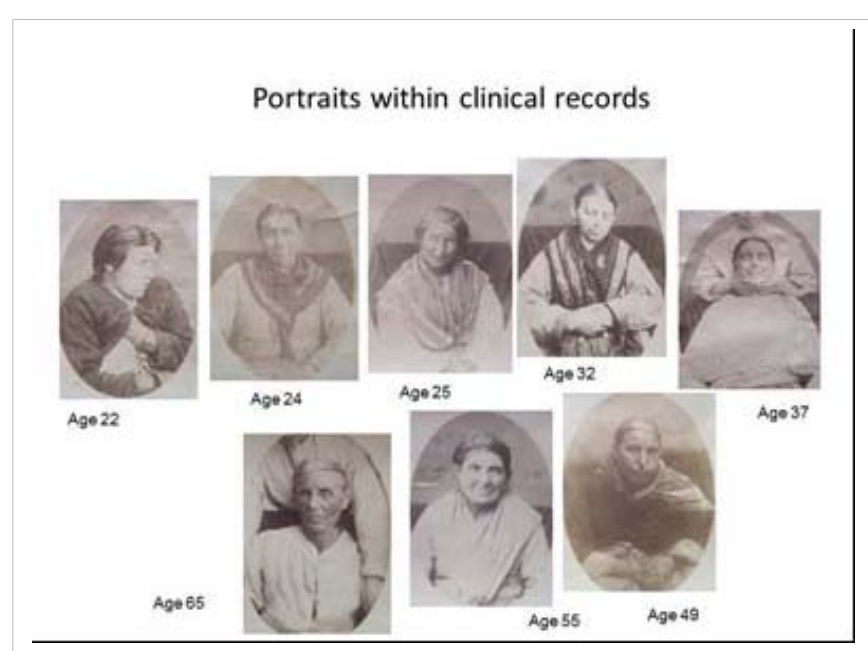

Figure 2: Portraits are inserted in the medical records of folder 661 - women dead, 1883. The numbers close to the portraits indicate the correspondent age.

\section{Methods}

Data sources are medical records written by psychiatrists, autopsy records and admission registers kept in the Venice San Servolo Archive. We included in the study all the folders of residents in the Province of Rovigo, admitted in the Psychiatric Hospital of Venice since November 1866 and discharged or died within the $31 / 12 / 1899$. For women, the observation period begins in 1873, when the women's section opened.

A team composed by a psychiatrist, a psychiatric nurse and two archivists has read, reviewed and digitized all the folders, registering all information included in them. An expert in biostatistics has blindly performed the statistical analysis. The considered parameters are: Municipality of residence, age at admission time, marital status, number of children, education level, work/occupation, date of admission, date of discharge or death, admission diagnosis, presence or absence of pellagra, clinical status at discharge and diagnosis of death. The data, stored according to the old Municipalities, have been reprocessed according to the current Municipalities: this allows for the comparison with the historical population series.

Data analysis was performed using descriptive statistics (mean, standard deviation, frequency distribution) both total and disaggregated in four groups: discharged males, dead males, discharged females, dead females. To deepen the descriptive analysis, binary variables were created, calculating correlations, looking for bivariate relationships between the different variables; the correlation indices range from - 1 (perfect negative relationship) to +1 (perfect positive relationship), while 0 represents the absence of a linear relationship between the variables. We used tetrachoric correlations in all our analysis since the considered variables were binary $[10,11,12]$. In order to avoid the Type I error, we applied the Bonferroni correction.

Statistical analysis was performed using STATA 13

\section{Results}

\section{Sample}

It consists of 940 folders, 462 of females and 478 of males; 532 folders belong to discharged subjects (293 males and 239 females), 408 folders to dead cases ( 185 males and 223 females). Only 5 folders, 1 male and 4 female, are missing.

The folders concern 820 people, as some cases had more than one hospitalization: 12 women and 17 men who died had been hospitalized beforehand and discharged. Among discharged cases, there are 55 people with more than one admission (up to 7): 32 males and 23 females.

On the date of 31/12/1899, 148 other cases, 74 males and 74 females, were still hospitalized at Psychiatric Hospital of Venice: they would carry on their course, until discharged or died, within the next three decades.

Personal and social parameters: A synthesis of sociodemographic characteristic of the sample is reported in table 1

Age: The age at admission is between 8 and 79 years in males and between 13 and 78 years in females. The average age at admission was 36.62 years for discharged subjects and 44.12 years for dead cases lower in females than in males. The average age of death was 46.62 years for women, 47.64 years for men.

In most cases, death occurs within the same decade of life from the entrance, with correlations from to 1.0, (males and females under 20 years) to 0.77 (women aged $41-50$ years), $p$ values $=0.000$. The distribution of age at admission in the various groups is illustrated in figure 3.

Marital status: 472 people were married, 316 unmarried, 124 widows and 28 with marital status not indicated (Figure 4). Only religious marriage, at the time un-effective for the State, is in this research equalized to civil marriage, for its great social acceptance. All males less than 20 years of age are unmarried and very few women are married; the age groups 31-40 and 41-50 years are generally associated with marital status. No man up to 40 years is a widower, while there are widows already in the age

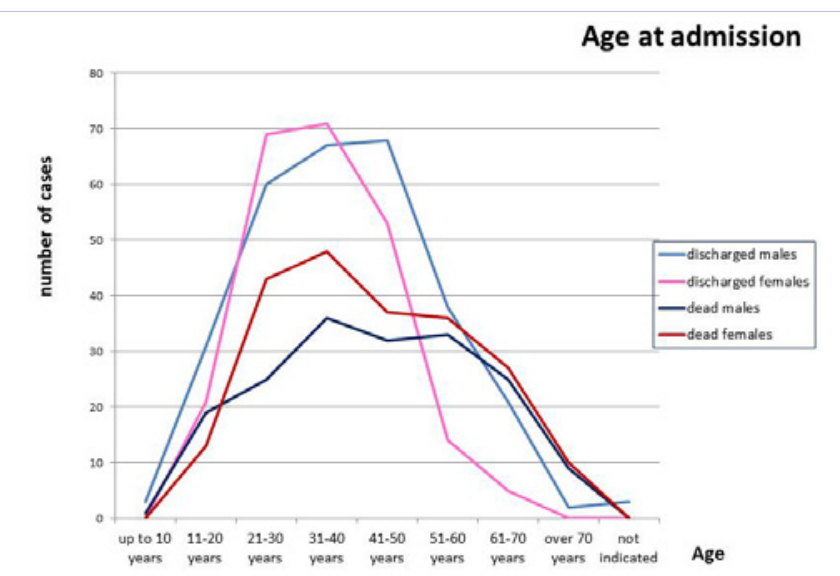

Figure 3: Frequency distribution of age at admission, genderdisaggregated and outcome disaggregated. 
group of 21-30. From 61 years on, there is a significant positive correlation with female widowhood in dead women $r=0.58$, $p=0.014$.

Children: The number of children is rarely mentioned in the men's folders, although there was a pre-printed space; moreover, the existence of dead children emerges only in 3 cases, by reading the clinical diary. The number of children is reported more often in the female group, probably because pregnancy is considered of medical interest. Taking into account the registered data, 20\% of women and $10 \%$ of men results to have four or more living children (Figure 5).

The documentation about dead children, which covers 56 folders is also more frequent for women; the case of a woman stands out, who was repeatedly hospitalized and had 15 dead children.

Single men did not have children while some single women did have them.

Educational level: The level of education is often defined in

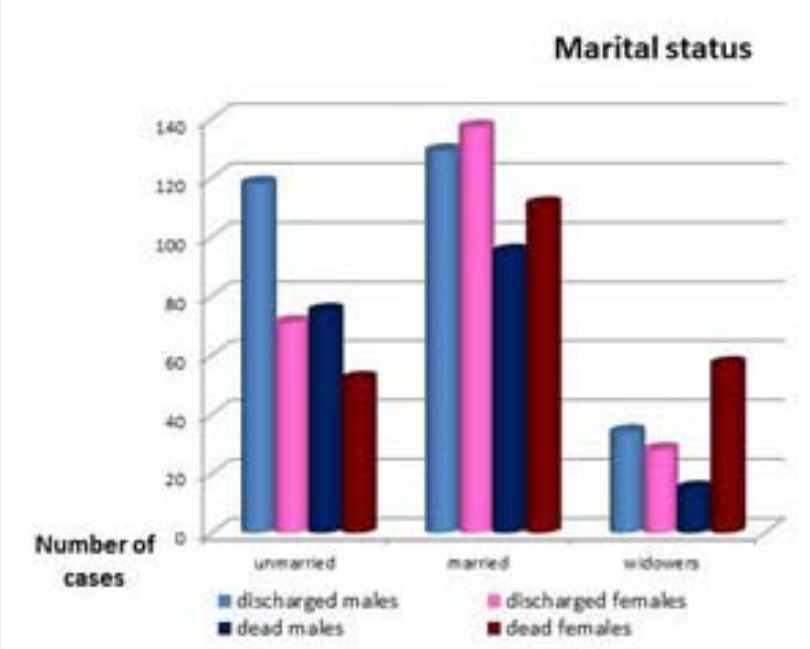

Figure 4: Frequency distribution of unmarried, married and widows/widowers, gender disaggregated.

\section{Number of children}
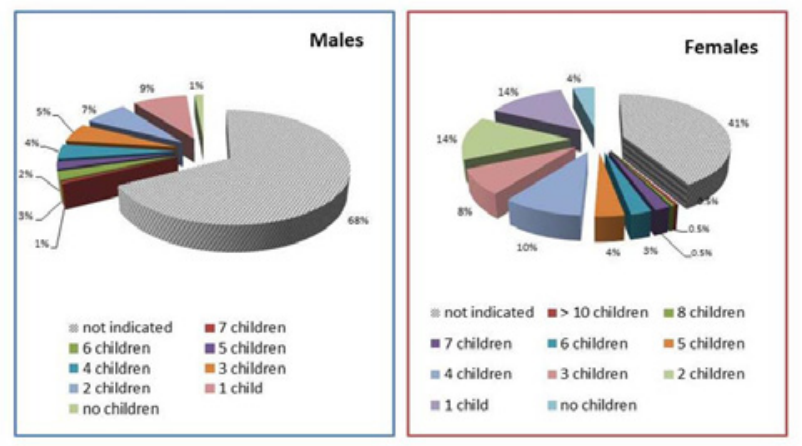

Figure 5: The graphics show the distribution of missing data (in grey) and of the number of children, in males and females.

\section{Educational level}

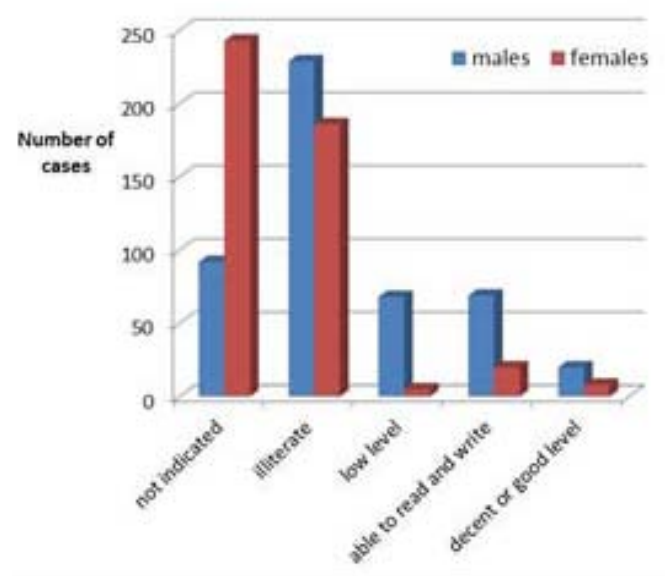

Figure 6: Frequency distribution of different levels of learning and education, gender disaggregated.

a generic way, with quantitative expressions such as "sufficient", "little", "fair" or thorough skills, such as knowing how to read or write. Only in a small number of cases the education is defined according to the achieved degree or the elementary class attended.

The distribution of education level is showed in table 1.

There is no information in $35.6 \%$ of the total cases, and in much greater proportion in females $(52.6 \%)$ than in males (19.2\%); illiterates are $68.6 \%$ of the sample and only $4.6 \%$ have a level of education indicated as decent or good (Figure 6).

Unmarried women are more educated than married women. All females over 50 years old and all men over 70 years old were illiterate.

Work/Occupation: The occupation (Figure 7) is almost always indicated for men, with the exception of 13 cases, including two children. Agricultural work is prevalent, with 202 people hired men or farm laborers and 28 working in cattle breeding. The craftsmen represent $18.4 \%$ of the population: shoemakers, carpenters, masons, barbers, bakers, millers, blacksmiths, furnace workers, rope makers, boat builders and painters. Traders constitute $10 \%$ of the population: innkeepers, vendors of coffee, fruit, fish, eggs, skins or various kinds, peddlers and mediators.

7 people are carters, 13 sailors, fishermen and boatmen, 12 are domestic servants, 12 are public employees: military, guards, a railway worker, a postal clerk, a teacher. 3 cases belong to religious orders. 8 cases have "recognized" occupations, such as beggars. Intellectual professions are rare: only two employees, one lawyer and one pharmacist.

Among women, the occupation is almost always a qualification of the role of the family, such as the 253 plow(wo) men, or within the family, such as 81 housewives . Only $11.9 \%$ of 


\section{Work/Occupation}

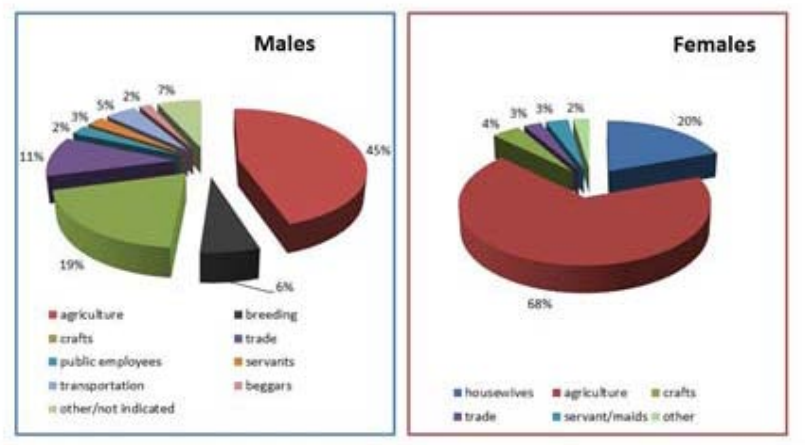

Figure 7: Distribution of work/occupation in males $(\mathrm{N}=478)$ and females $(\mathrm{N}=462)$.

women have their own work: they are artisans, sellers of fruit, coffee or coal, workers, washerwomen or prostitutes. There are 15 seamstresses, tailors and spinners, 14 domestic servants, 2 teachers and 5 beggars.

Women over age 50, especially widows, were often traders; young unmarried females were frequently craftswomen.

The farmers were more often illiterate, with significant correlation in discharged males $(\mathrm{r}=0.53, p=0.000)$; males traders had some level of education, as well as craftswomen or housewives. No public employee was illiterate.

Poverty: Almost all the admitted people were in misery. In fact, in 935 cases $(99.47 \%)$ the administrative folders include a certificate of poverty, indicating the absence of ownerships or land rents and minimal incomes; in many cases, indeed, the certificate declare the absence of any type of income and a condition of absolute misery.

\section{Clinical Parameters and Outcomes}

Trend of hospitalizations over the years and seasonality: 1088 admissions from Polesine throughout 33 years: it means, on average, one admission each 197 inhabitants. The days of hospitalizations in the studied period are, in total, more than one million (1010417), with an average of 4.7 days per capita. The distribution of cases in the different Municipalities varies: some municipalities have a high number of hospitalizations related to population, with a ratio 1:76, one admission each 76 inhabitants; others have a very low ratio, 1:1574, one admission each 1574 inhabitants. Similarly, the number of days of hospitalization per capita ranges from 10.37 to 0.58 days per person.

The total number of admissions per year ranges from a minimum of 2 (1867) to a maximum of 79 (1880); the period with the highest number of hospitalizations for both genders is between 1879 and 1883 .

The admissions were more frequent in spring and summer, between May and August, and less frequent in fall and winter, although with a peak in December. A significant percentage of admissions to the Psychiatric Hospital, particularly for women, were preceded by a variable period of hospitalization (from a few days to several months) in the local General Hospitals of the Province, an impossible period to be quantified in many cases.

The output from the Psychiatric Hospital occurred by discharge or death, with a ratio_discharged/dead of 1.29. In some years $(1875,1888,1891,1892,1897,1899)$ the number of deaths exceeds that of the discharges (Figure 8).

Diagnosis of admission: (Figure 9) In males ( $\mathrm{N}=478$ ), the pellagra diagnosis is dominant (183 cases). The disease was named pellagrous "phrenosis", pellagrous mania, pellagrous melancholia or pellagrous dementia. Signs of pellagra, cutaneous or gastrointestinal, are still reported in 228 cases, almost half of the sample $(47.7 \%)$.

Melancholy, defined also as "lipemania", simple or with astonishment, is very common, with 121 cases. Mania is also very represented, with 95 cases, often accompanied by more specific etiology (e.g. vascular or after meningitis), the type of symptoms (with or without fury), the content of delusions (vague, religious or persecutory) or the time course (circular).

Other frequent diagnoses are: dementia of various origins (primitive, paralytic, alcoholic, epileptic) with 25 cases; paralytic phrenosis (21 cases), alcoholic phrenosis (20 cases), epilepsy (15), and idiocy (10). Infrequent diagnoses are: sensorial phrenosis, moral insanity, intellectual monomania, hypochondria, senile phrenosis, meningitis, circular insanity. In 3 cases, the diagnosis is non-existent or unreadable. One case was defined "not insane".

Even in females $(\mathrm{N}=462)$, the prevalent diagnosis is pellagra
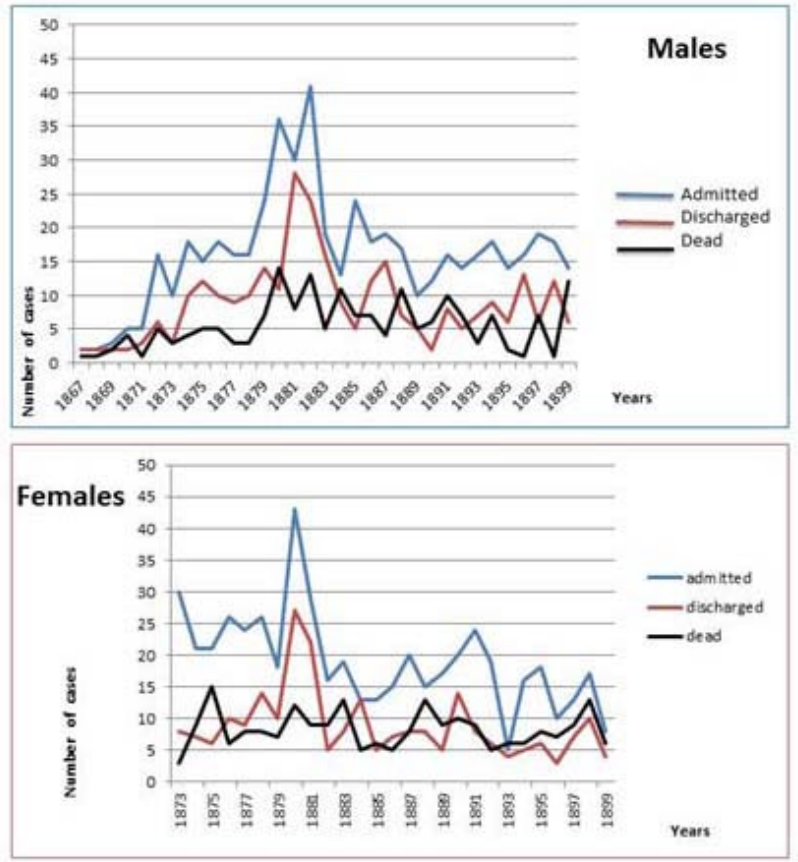

Figure 8: Hospitalizations from Polesine: trend of admissions, discharges and death in males, above (1867-1899) and females, below (1873-1899). 


\section{Diagnosis of admission}
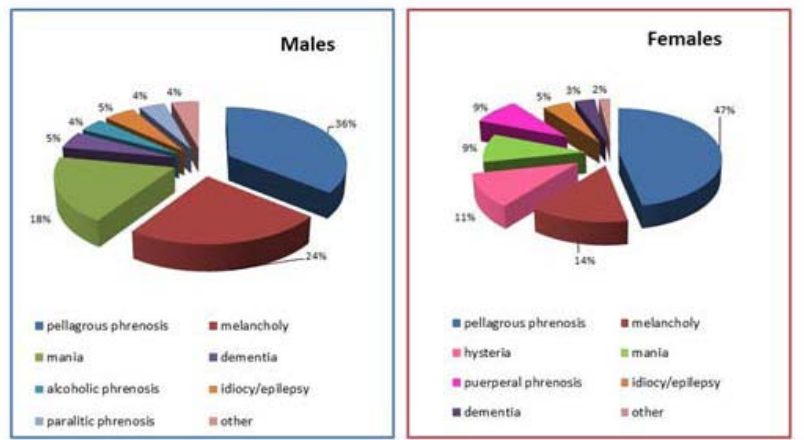

Figure 9: Distribution of diagnoses of admission in males and females: pellagra diagnosis (in blue) is prevalent. Hysteric and puerperal "phrenosis" are peculiar in females.

(212 cases), in its variants with melancholy or mania or delusion. Symptoms of pellagra are present in 266 cases, more than half of the sample (57.6\%). Peculiar diagnosis in females is hysterical phrenosis - absent in males - with 50 cases and puerperal phrenosis with 39 cases.

Among the frequent diagnoses is melancholy (63 cases), 8 of which with astonishment, and mania (42 cases), 15 of which with fury. There are 16 cases of dementia, 12 of idiocy and 10 of epilepsy. Infrequent diagnoses are monomania, alcoholic phrenosis, paralytic phrenosis and hypochondria.

Pellagra, in all its symptomatic manifestations shows a significant positive correlation with the work in agriculture: $\mathrm{r}=0.59(p=0.0000)$ in discharged males, $\mathrm{r}=0.58(p=0.0001)$ in dead males and $\mathrm{r}=0.56(p=0.0000)$ in discharged females; it correlates also positively with a lack of education: $r=0.57(p=0.0000)$ in discharged males and $r=0.59(p=0.0000)$ in dead males. Pellagra correlates negatively with age 21-30 years in discharged females $(\mathrm{r}=-0.51, p=.002)$ and unmarried status in discharged males ( $\mathrm{r}=-$ $0.39, p=0.012$ ) and in discharged females ( $\mathrm{r}=-0.57, p=0.0001)$. It negatively correlates with the work as housewife in discharged women ( $r=-0.62, p=0.000)$ and the work as merchant in discharged males $(\mathrm{r}=-0.64, p=0.015)$.

Mania is more common in young people, both males and females. Idiocy and epilepsy correlate positively with the unmarried status in dead females $(\mathrm{r}=0.84, p=0.0000)$.

Hysterical phronesis, mainly associated with the housewife occupation and with the unmarried status, negatively correlates with the presence of pellagra $(\mathrm{r}=-0.73 . p=0.0000)$. The diagnosis does not appear in the group above the age of 60 years.

The puerperal phronesis is more frequent in the age group of 21-30 years and in the housewives.

Duration of hospitalization or survival after admission: The duration of hospitalization, in the discharged group, has a very wide range: from 16 to 5091 days in males, with an average of 348.36 (standard deviation 641.78) and from 13 to 5055 days in females, with an average of 491.35 (standard deviation 696.87).

The survival after admission, in the dead group, ranges from 5 to 8881 days in males, with an average of 900.06 (standard deviation 1410.1) and from 2 to 9123 days in females, with an average of 1069.11 (standard deviation 1526.3).

The pellagra cases were often associated with death within the first 100 days of hospitalization. In order to analyze the socioeconomic factors influencing the probability of earlier death in this group, we used a multivariate analysis, implementing a logit regression that has the following covariates: age, sex (female), occupation (agriculture), marital status (married), and education level (illiterate), presence of children. All the covariates are binary variables except age.

The results show that, to work in agriculture increases three times the probability of earlier death by pellagra than having any other type of occupation; to be illiterate dramatically increases (by almost fifteen times) the probability of earlier death by pellagra; the age of patient is positively related to earlier death as well (Table 2).

Considering the entire male group, we can observe that the children did not survive more than a year; over 20 years, the chances of dying in a short period of time increased in proportion to the age; married males having children died generally earlier than unmarried. Among women, there are no statistically significant correlations between survival time and age or marital status, even if unmarried and young women seem to have better probabilities of survival. In the females group, the admission diagnoses of hysteria, puerperal phrenosis and mania associated with better survival probabilities; in the male group, this happens for melancholia diagnosis.

Outcomes: A significant percentage of admissions (43.4\%) ended with the death of the patient into the Psychiatric Hospital, significantly more likely in females $(48.3 \%$ of deaths) than in males $(38.7 \%$ of deaths). The Pearson chi-square $2(1)$ is 8.7506 , with $\mathrm{p}=0.003$. When the hospitalization ended with a discharge, the outcome was defined as "healing" (53.9\% of cases), "improvement" (37.8\%) or "no improvement" (4.7\%); rarely the discharge occurred after a request of the family or of the Municipality, regardless of clinical status (3.6\%) (Figure 10).

Diagnosis of death: (Figure 11), the most frequent diagnosis of death (50 cases) in men was the wasting away, often defined "pellagrous". 34 cases died of inflammatory or infectious brain diseases (meningitis or encephalitis, acute or chronic, periencephalitis and progressive paralysis), 18 of gastrointestinal pathology(diarrhea, enteritis, often associated with pellagra), 18 of tuberculosis, 17 of cerebrovascular diseases (apoplexy, congestion or brain hemorrhage, paralysis and hemiplegia), 13 of respiratory infections (pneumonia and bronco-pneumonia), 11 of heart diseases (pulmonary edema, infarction, pericarditis), 8 of epilepsy. Other diagnoses of death are: septicemia, gangrene, lymphadenitis, erysipelas, scurvy, senile dementia. In 6 cases, the causes are uncertain or unspecified; in 9 cases they are 
Table 1: Socio-demographic characteristics in discharged and dead groups, gender disaggregated.

\begin{tabular}{|c|c|c|c|c|c|c|c|c|}
\hline & $\begin{array}{c}\text { Total } \\
\text { males }\end{array}$ & $\begin{array}{c}\text { Total } \\
\text { females }\end{array}$ & $\begin{array}{c}\text { Discharged } \\
\text { males }\end{array}$ & $\begin{array}{c}\text { Discharged } \\
\text { females }\end{array}$ & $\begin{array}{c}\text { Total } \\
\text { Discharged }\end{array}$ & $\begin{array}{l}\text { Dead } \\
\text { males }\end{array}$ & $\begin{array}{c}\text { Dead } \\
\text { females }\end{array}$ & $\begin{array}{l}\text { Total } \\
\text { Dead }\end{array}$ \\
\hline N. Folders & 478 & 462 & 293 & 239 & 532 & 185 & 223 & 408 \\
\hline $\begin{array}{l}\text { Mean age at the } \\
\text { admission }\end{array}$ & 40.87 & 38.95 & 37.99 & 34.95 & 36.62 & 45.15 & 43.28 & 44.12 \\
\hline Mean age of death & -- & -- & -- & -- & -- & 47.64 & 46.62 & 47.08 \\
\hline \multicolumn{9}{|l|}{ Marital status } \\
\hline Unmarried & 193 & 123 & 118 & 71 & 189 & 75 & 52 & 127 \\
\hline Widows/widowers & 49 & 85 & 34 & 28 & 62 & 15 & 57 & 72 \\
\hline \multicolumn{9}{|l|}{ Educational level } \\
\hline Illiterate & 229 & 186 & 140 & 105 & 245 & 89 & 81 & 170 \\
\hline Low level & 68 & 5 & 50 & 4 & 54 & 18 & 1 & 19 \\
\hline Able to read & 69 & 20 & 53 & 14 & 67 & 16 & 6 & 22 \\
\hline Not indicated & 92 & 243 & 39 & 110 & 149 & 53 & 133 & 186 \\
\hline \multicolumn{9}{|l|}{ Work/occupation } \\
\hline Agriculture & 213 & 285 & 139 & 140 & 279 & 74 & 145 & 219 \\
\hline Cattle breeding & 29 & -- & 16 & -- & 16 & 13 & -- & 13 \\
\hline Craft & 88 & 20 & 57 & 12 & 69 & 31 & 8 & 39 \\
\hline Trading & 40 & 10 & 23 & 6 & 29 & 17 & 4 & 21 \\
\hline Housewives & -- & 79 & -- & 47 & 47 & -- & 32 & 32 \\
\hline Public employees & 12 & 2 & 7 & 2 & 9 & 5 & -- & 5 \\
\hline Other & 64 & 26 & 38 & 11 & 49 & 32 & 15 & 47 \\
\hline Not indicated & 32 & 40 & 19 & 21 & 40 & 13 & 19 & 32 \\
\hline Poverty & 475 & 459 & 292 & 237 & 529 & 184 & 222 & 406 \\
\hline
\end{tabular}

Table 2: Logit regression: the dependent variable is pellagra diagnosis with death within 100 days of hospitalization, the covariates are as follows: age, sex (female), occupation (agriculture), marital status (married), and education level (illiterate), presence of children. All the covariates are binary variables except age.

\begin{tabular}{|c|c|}
\hline & Odds ratio \\
\hline \multirow[t]{2}{*}{ Age } & $1.032^{* *}$ \\
\hline & $(0.013)$ \\
\hline \multirow[t]{2}{*}{ Female } & 0.439 \\
\hline & $(0.589)$ \\
\hline \multirow[t]{2}{*}{ Agriculture } & $2.835^{* *}$ \\
\hline & $(0.466)$ \\
\hline \multirow[t]{2}{*}{ Married } & 0.758 \\
\hline & $(0.485)$ \\
\hline \multirow[t]{2}{*}{ No education } & $14.756^{* * *}$ \\
\hline & $(1.032)$ \\
\hline \multirow[t]{2}{*}{ Child } & 1.655 \\
\hline & $(0.606)$ \\
\hline \multirow[t]{2}{*}{ Cons } & $0.003^{* * *}$ \\
\hline & $(1.258)$ \\
\hline$N$ & 173 \\
\hline chi2(df.) & $20.054(8)$ \\
\hline r2_p & 0.178 \\
\hline Correctly classified & $79.19 \%$ \\
\hline Hosmer-Lemeshow chi2(df.) & $4.25(8)$ \\
\hline \multicolumn{2}{|c|}{ Robust standard errors in parentheses ${ }^{*} p<0.10,{ }^{* *} p<0.05,{ }^{* * *} p<0.01$} \\
\hline
\end{tabular}


unreadable. In many cases, it is reported gangrene of bedsores, too.

In women, the leading diagnosis of death is gastrointestinal pathology (dysentery, enteritis or gastroenteritis) with 41 cases and pulmonary or intestinal tuberculosis, with 41 cases.

25 women died of lung infections other than tuberculosis, 21 with infection or inflammation of the brain (edema, encephalitis, meningitis, peri-encephalitis), 20 of cardiac or pulmonary edema, 16 of generalized infectious diseases (septicemia, gangrene, erysipelas, smallpox, tetanus, typhoid), 14 of cachexia and "wasting away", 13 of cerebrovascular diseases (stroke, hemorrhage, embolism, paralysis), 4 of malignancies (two bowel cancer, one sarcoma and one melanoma). Other diagnoses of death are: chorea, epilepsy, lymphadenitis, and fever without other indications. The diagnosis is absent in two cases.

Tuberculosis as diagnosis of death is absent in males above 50 years and females above 70 years; heart disease does not occur as a cause of death in males up to 20 years old and females up to 30 years.

In males, the death due to infection or inflammation of the brain negatively correlates with pellagra as admission diagnosis ( $\mathrm{r}=-0.75, p=0.0005)$; the death due to cachexia, instead, shows a significant positive correlation with pellagra diagnosis $(r=0.79$, $p=0.0000$ )

There is no statistically significant correlation between diagnosis at the admission time and diagnosis of death, in the females group.

There is a statistically significant difference in the pattern of diagnosis of death as a function of sex, as indicated by chi-square analysis (Pearson chi- square $(8)=50.67, p=0.000$ ).

\section{Discussion}

The examined medical records - nearly a thousand - provide

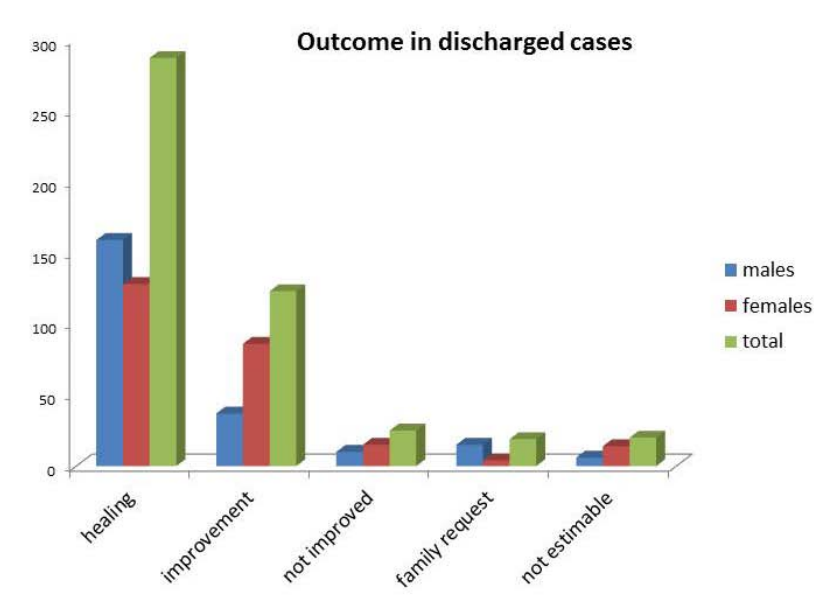

Figure 10: Frequency distribution of outcome in discharged patients, total and gender disaggregated. Healing and improvement, on left, are more frequent than not improvement and family request.

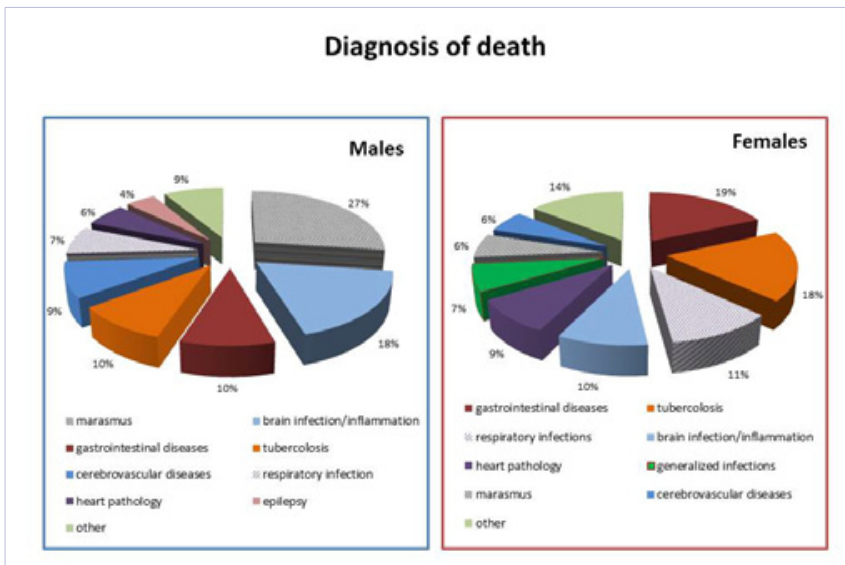

Figure 11: Diagnosis of death in males, on left, and females, on right.

a large amount of social and clinical information.

People of all ages were admitted to the Psychiatric Hospital, from children ( 8 and 13 years the youngest) to seniors (78 and 79 years); mostly, they were adults, from 21 to 50 years of age. Women were younger than men at admission, and the people who were then discharged were younger than those who had died. Unmarried people prevailed among the young and married people among adults. There were widowers and especially widows above 50 years of age, with a fairly predictable distribution. Curious is the fact that, over the 60 years, widowhood associated more with discharge rather than with death, behaving as a condition of lower risk.

Early marriages were rare, except for the dead female group, indicating it as a potential factor of negative prognosis. The presence of children was a rare event in females under 20 years, and none of the males of this age had children.

The number of children is a largely incomplete element, particularly in males (68\% of missing data) and it is further misrepresented by the lack of indication of the died children, which appears only, anecdotally, in the female group; even so, however, it is evident that the death of the children was a fairly common phenomenon, covering at least one-tenth of the cases. Despite the rigid morality, the clinical records show that children did exist also outside the marriage.

The level of education was very poor, with illiteracy at around 40-47\%; it was not due to a condition of marginality, but it reflected here the similar condition of the entire population of Polesine and of Italy, as indicated by the historical series of the Institute of Statistics [13], even though the law provided for the compulsory and free education for at least two elementary classes since 1877.

The absence of data on education in over half the females in our sample may, however, indicate a lack of interest of the physicians about this issue, probably regarded as irrelevant in women.

The list of jobs carried out by the alienated reflects the poorest 
- and predominant - area of the society at the time. Agriculture occupied, permanently or precariously, about half of this series: the men for direct engagement and the women for similarity, linked to familial status. Only $12 \%$ of women had their own job: apart from the two teachers, it was usually an unpretentious and poorly paid job. Housewives seemed to have a slightly better economic condition than farmers, while remaining in a level of poverty.

In summary, the sample of the alienated reflects the characteristics of the population of origin that was devoted to agriculture, had a very low level of education, was weighed down by heavy family burdens and numerous griefs and characterized by extreme poverty and arduous living conditions. It is no coincidence that the great immigration from Polesine started in this period: between 1876 and 1899, 30\% of the population immigrated to the Americas, especially to Brazil $[14,15]$.

The clinical information is, in our opinion, the most interesting aspect of this research, which has led us to review the individual folders, to see the clinical diaries and the autopsy reports, to identify doctors from the different writings and from the used style, to occasionally find reported speeches of patients and to see their faces in photographs.

Municipality doctors identified mentally ill people and fixed a diagnosis. Those diagnoses, reported in the Psychiatric Hospital medical records, were often generic, based on the most obvious symptoms, affected by the large variability of judgment - and sometimes prejudice - of different doctors, without specific psychiatric knowledge. This reduces the reliability of the parameter, distorting any correlation with other factors. A comparison with the current psychiatric nosography, for example, is very difficult and it would require a very careful examination of clinical reports of the entire sample.

Melancholy is, in this sample, more frequent in men and could be comparable to the depressive syndrome. In many cases, however, serious organic diseases emerge, as consequences of a stroke, heart diseases or generalized infections. In particular, melancholy with stupor frequently associated with yet undetected tuberculosis. Similarly, the craze is sometimes used as a synonym for generalized agitation, even if, in some cases, it completely satisfies the current diagnostic criteria for mania.

Dementia is a very heterogeneous category, further labelled as primitive, paralytic, alcoholic, epileptic or senile, indicating a kind of final common pathway for different etiologies. Surprisingly, it is never been diagnosed in over 60 years, in this sample.

People affected by epilepsy were admitted to psychiatric hospital: young, unmarried, without a job, with little chance of discharge and high probability of death. If they survived, their clinical reports were characterized by negative adjectives (e.g. lazy, bad, liar, spiteful), all considered as an expression of the epileptic "character", a prejudice sometimes still occurring.

Hospitalized children, brain damaged and with multiple handicaps, was sent to the hospital with unrealistic expectations of education, for the "inability to supervise them". The same motivation - supervision - was the reason for the hospitalization of the elderly, who often belonged to large families. The myth of the great patriarchal family and the bucolic welcoming society of the past, seen from this observatory, is more like a fairy tale than a reality: the "real" reality was that for unproductive people, in need of care, there was no place in the family, even at the time.

Females received a particular diagnostic labeling: puerperal phrenosis (when they became ill after childbirth or during breastfeeding, regardless of symptoms) and hysterical phrenosis. This last category was used almost exclusively for the unmarried women, regardless of symptoms and, in this sample, without any significant correlation with all other parameters. Instead, the doctors' opinion, or prejudice, appears relevant: they describe these women as plaintive and able to cry for nothing, but the clinical records or the autopsies later show serious diseases such as tuberculous peritonitis or neurological lesions.

In the folders of this research, it is very difficult to recognize schizophrenia, nowadays the major psychosis, not yet defined as a syndrome at the time; only sporadic cases could satisfy the diagnostic criteria. The psychiatric classification has changed a lot over the course of a century: by applying the current labels, most of the cases of this sample would belong to the category "Mental Disorders due to a General Medical Condition".

The prevalent disease in the studied group was pellagra, with about half of the cases; it was easily diagnosed for the characteristic symptoms, especially skin erythema. Underestimation was possible, being that the illness was so extensive and chronic to be considered negligible. In Polesine, $37.07 \%$ of the population was affected [16,17].

Pellagra had appeared sporadically in Italy in the seventeenth century and had spread in the next century, with the increasing expansion of crops of corn. Initially introduced as food for times of famine, corn became a preferred culture, especially in the fertile valley of the Po river, for high yield and gains related to it [18]. In the nineteenth century, the ownership of land gradually shifted from farmer to great owners, who lived elsewhere, and had the power to reduce at will the wages of laborers and the percentages of crop due to sharecroppers. The vast wealth of the rich meant increasing the number of the poor and their misery. Their only food was corn, in the form of polenta.

The exclusive maize feeding initially caused weakness and typical skin lesions, such as photosensitive erythema, ulceration and severe itching. Over time, chronic diarrhea appeared, resistant to any treatment. Neurological symptoms subsequently appeared, such as proprioceptive sensibility disorders, paresthesia and psychiatric symptoms, as hallucinations, delusions, insomnia, agitation, catatonia, confusion and cognitive deficits. Our sample shows this typical course of the disease.

Municipality doctors and teachers, living in contact with the population, were deeply aware of the link between the disease and misery [19,20]; "specialists", meanwhile, discussed etiology elsewhere. Many of them argued that it was contagious or hereditary, because entire families had pellagra; others [21] supported the theory of spoiled corn, badly preserved by ignorant 
peasants. People got sick in spring when they ended the food supplies of the previous harvest; in the years of famine, the illness increased. Most probably, this was the cause of the increase in hospitalizations in the years 1879-81: raising taxes and falling wages plunged large sections of the population from poverty to hunger, significantly increasing the requests for admission. This resulted in an increase in turnover, being unchanged the number of available beds.

At last, Goldberger [22], an epidemiologist of the United States Public Health Service, understood and demonstrated the correlation between the disease and the lack of some food elements, stating that it was prevented with a well-balanced and varied diet. However, this was afterwards; in the twentieth century the deficiency factor was identified in niacin or PP Pellagra Prevention- vitamin $[23,24]$.

In the present research, the people mostly affected by pellagra are peasants, particularly women and elderly men; it was also more common in married people with children. Probably, where food was scarce and competition increased, the weakest or the most altruistic were more malnourished than the others. In addition, it is very interesting to note that, with the same living conditions, the presence of education, however small, was associated with a lower likelihood of pellagra.

In the first decades of the twentieth century pellagra in Polesine decreased, with the establishment of food dispensaries, but it was eradicated only by the improvement of living conditions in the second half of the twentieth century.

Currently, the disease is reported sporadically [25,26], in association with anorexia nervosa [27], chemotherapy and use of isoniazid [28] or chronic alcoholism [29]. In many parts of the world, however, the living conditions are similar to those of Polesine in the nineteenth century, perhaps even worse: in places where hunger is endemic, pellagra-like syndromes are highly probable. And how many other deficiency diseases can cause psychiatric disabilities? In all these cases, the first choice therapy is the improvement of living conditions.

What happened to the people after the admission in Venice Psychiatric Hospital? Some of the admitted patients were already very ill at the admission time and died after a few days or within the first three months the most vulnerable were children, elderly men and married adults having children. Those who rode over the first few months and were able to eat and digest food, despite the widespread diarrhea, had a good chance of surviving. In fact, the availability of food was probably the main psychiatric therapy at the time.

However, many people remained in the hospital for their entire life, in a state of chronic and progressive deterioration, with a very high probability of becoming ill of infections such as tuberculosis, erysipelas, trachoma, intestinal parasitic infections, pneumonia and meningitis. The probabilities of dying at the hospital were high $(43.4 \%)$, particularly in women (48.3\%). Perhaps women died more than men due to the greater malnutrition, but the possibility of a different incidence of morbid events should be considered: hospitalized in two different islands, although not far away, there were different chances of the spreading of contagious diseases. It is interesting to highlight that the feminine particular diagnoses, hysteria and puerperal phronesis, associated with a better survival probability.

In some years, the number of dead people was higher than that of discharged people: the "black" years for Polesine cases are 1880, 1884, 1888, 1891, 1899; among them, only 1888 and 1891 show a similar trend in the entire Hospital population. Elderly males died especially of marasmus, often linked to malnutrition and pellagra, and for infectious or inflammatory brain illnesses; young females died mainly because of tuberculosis or gastrointestinal diseases. The infections of all kinds, in the absence of effective treatments, were almost always fatal; people staying in bed, for various reasons, ended up dying soon for bedsores.

Nevertheless, many people, more than half, improved: the improvement concerned firstly the physical conditions and secondly the psychic conditions. The agitation ceased, the symptoms decreased and people began to work within the asylum. Reading the case reports, a "positive outcome standard" emerges, consisting of: an initial phase of acute symptoms, followed by clinical improvement and work in the various internal areas (laundry, shoe repairs, carpentry, tailoring, agricultural colony for men and sewing or cleaning and tidying for women), diligence about work and finally discharge. The skilled workers were discharged in a short time, although still partially symptomatic, considering not just the symptoms, but also the social utility and the reintegration through work. The mean duration of hospitalization, in the discharged group, was significantly higher in women than in men, with about 18 months versus 11 months, indicating greater chronicity or worst psychophysical state at admission or lower incentives at discharge or perhaps a greater "protection" by the therapists.

The duration of hospitalization was related to clinical factors, such as the severity of symptoms or general physical condition. It related also to external parameters such as family demands or Municipality orders, which could accelerate or delay the discharge. In many cases, there is a great difficulty in dismissing people already declared healed, because no one was going to collect them. The event was common enough to lead to administrative measures, such as placing the daily rate to the account of municipalities.

Among discharged people, the prevalent outcome was healing (53.9\% of all cases), without difference between males and females, and the improvement was also frequent (37.8\%). Very few patients had a "revolving-door" trend, with frequent discharges and readmissions. Where then does the common belief that mental illness is incurable originate from, if people could heal even in a time when there were no effective treatments, and the policy of care was only the insane asylum?

\section{Gender}

Relevant gender differences emerge in the sample of this 
study: women, less educated than men, get sick at a younger age, remain hospitalized longer, are more likely to die within mental hospital and are subject to different diagnostic criteria. Could worse prognosis be related to a general lack of rights of females in the Polesine population? It is one of the possible hypotheses. At the time, women had fewer rights than men: without the right to vote, they passed from the father's to the husband's tutelage and were in a position of subordination within and out of the family.

\section{Poverty}

One of the most relevant results of this research is the prevalence of poverty $(99.47 \%)$ in the present sample. The World Health Organization emphasizes the close link between poverty and lack of health, which is "deeply intertwined with disempowerment, marginalization and exclusion" [30,31] and highlights that mental health is an integral part of health and well-being: "No health without mental health" [32].

The correlation between mental health and poverty emerges from numerous literature data [33,34]. People affected by mental diseases are often marginalized and fall down in "acquired" poverty [35], but poverty itself can cause diseases, reducing availability and accessibility to resources or acting as a risk factor through economic stressors [36]. Children raised in poverty and chronic hunger have an increased risk of psychiatric illnesses [37].

Mental diseases result also in high financial burden for individual and society, leading to lack of productivity, inability to work and need for care.

Poverty precedes the mental illness in more than half of the cases of this research.

In this sample, malnutrition and poor living conditions results as the main causes of illness and hospitalization.

\section{Conclusions}

The retrospective study of the Archive's documents makes large case series available to us, from the onset to the outcome of disease, and allows us to review them using the current knowledge.

The most salient results of this study, which concerns the entire alienated population of a geographical area, the Polesine, in our opinion are:

- The high number of admissions, compared to the inhabitants: one admission every 197 inhabitants, over thirty years;

- The existence of gender differences in course and outcome;

- The high probability of dying within the hospital, which covers almost half of the cases;

- The high probability of healing, in survivors;

- The high percentage, over $2 / 3$, of mental illness from organic cause, which should make us reflect on the rigid division that many health professionals create between diseases of the mind and diseases of the body.

The most significant result is the extent of poverty in the group of admitted patients and in the entire population of the Polesine. The alienated represented the tip of the iceberg, the most fragile or more "agitated" elements of entire families suffering from malnutrition and pellagra, from generation to generation. Many people died of disease, others would be sick in subsequent years. In this population living under the poverty line, those who did not die quickly had a very high cost of assistance.

We should reflect on this lesson from the past from a social point of view, also in terms of economics and health planning. If many people are poor, many people will be sick. Beyond a critical threshold, it is not possible to ignore them and consequently public administrations end up having to pay the cost of poverty.

At present, health policies often aim toward a disinvestment of public health services and prevention; it would be useful to ask ourselves how today's savings (or "cuts") will result in future spending.

\section{Acknowledgements}

We would like to express our acknowledgment to Ms. Bonnie Maldonado for her language revision and her suggestions. We express our gratitude to Dr. Lucio Strumendo, who decided to establish the Venice Psychiatric Hospital Archive.

\section{Declarations}

Conflict of interests: There is no conflict of interest.

Ethical approval and clinical trial registration: This work doesn't require ethical approval or clinical trial registration.

\section{References}

1. Ketelaar E. Tacit Narratives: The Meanings of Archives. Archival Science 2001; 1(2): 131-41.

2. Vico G. Principj di una Scienza Nuova, Libro quinto. Napoli: Stamperia Muziana; 1744.

3. Franzina E. Merica! Merica! Venezia: Cierre; 1994. Italian.

4. Vanzan Marchini NE. San Servolo e Venezia. Un'isola e la sua storia. Venezia: Cierre; 2004. Italian.

5. Lovric M. The islands of the mad. Hidden Europe. 2007; 17.

6. Granger B. San Servolo, l'ile des fous. Psychiatrie, Sciences Humaines, Neurosciences. 2009; 7: 3-4.

7. Salviato A. Pellagra e pazzia: i manicomi di San Servolo e di San Clemente. Roma: Istituto della Enciclopedia Italiana; 2002. Italian.

8. Galzigna $\mathrm{M}$, Terzian $\mathrm{H}$, editors. L'archivio della follia. Il manicomio di San Servolo e la nascita di una Fondazione. Venezia: Marsilio; 1980. Italian.

9. Wilms W. San Clemente. Storia di un'isola veneziana. Uno dei primi manicomi femminili in Europa. Venezia: Centro tedesco di studi veneziani; 1993. Italian.

10. Leti G, Cerbara L. Elementi di Statistica Descrittiva. Bologna: Il Mulino; 2009. Italian. 
11. Brown MB, Benedetti JK. On the mean and variance of the tetrachoric correlation coefficient. Psychometrika. 1977; 42: 347-55.

12. Anderson TW. An introduction to multivariate statistical analysis. Hoboken: Wiley; 2003.

13. Italian National Institute of Statistics ISTAT.

14. Sori E. L'emigrazione italiana dall'Unità alla seconda guerra mondiale. Bologna: Il Mulino; 1979. Italian.

15. Anonymous. Veneto tra ottocento e novecento.

16. Zerbinati L, editor. Granoturco e pellagra nella vita rurale dell'Italia di ieri. Badia Polesine: ISeRS; 2000. Italian.

17. Ministero Agricoltura e Commercio. La pellagra in Italia, 1879. Annal di Agricoltura 1880; 18.Italian.

18. Messedaglia L. Il mais e la vita rurale italiana. Saggio di storia agraria. Piacenza: Federazione Italiana dei Consorzi Agrari; 1927. Italian.

19. Bertolotti C. La pellagra. Bibliografia degli studi dal 1776 al 2005. Mantova: Istituto Mantovano di Storia Contemporanea. 2009; Italian.

20. Mariani-Costantini R, Mariani Costantini A. An outline of the history of pellagra in Italy. Journal of Anthropological Sciences. 2007; 85: 16371.

21. Lombroso C. Trattato profilattico e clinico della pellagra. Torino: Fratelli Bocca; 1892. Italian.

22. Goldberger J, Waring CH, Willets DG. The Treatment and Prevention of Pellagra. Public Health Reports. 1914; 29(43): 2821-5.

23. Elvehjem CA, Madden RJ, Sttrong FM, Wolley DW. Relation of nicotinic acid and nicotinic acid amide to canine black tongue. J Am Chem Soc. 1937; 59(9): 1767- 8.

24. Harris LJ. The Vitamin B2 Complex. Further notes on "Monkey Pellagra" and its cure with Nicotinic Acid. Biochem J. 1938; 32(9): 1479-81.

25. Wang W, Liang B. Case report of mental disorder induced by niacin deficiency. Shanghai Arch Psychiatry. 2012; 24(6): 352-4. doi: 10.3969/j.issn.1002-0829.2012.06.008.
26. Pila Pérez R, Pila Pelàez R, Holguin Prieto VA, Torres Vargas E, Rosales Torres P. Pelagra: enfermedad antigua y de actualidad. Archivo Médico de Camagüey. 2013; 17(3): 381-92.

27. Jagielska G, Tomaszewicz-Libudzic CE, Brzozowska A. Pellagra: a rare complication of anorexia nervosa. Eur Child Adolesc Psychiatry. 2007; 16(7): 417-420.

28. Stratigos JD, Katsambas A. Pellagra: a still existing disease. Br J Dermatol. 1977; 96(1): 99-106.

29. Oldham MA, Ivkovic A. Pellagrous encephalopathy presenting as alcohol withdrawal delirium: A case series and literature review. Addict Sci Clin Pract. 2012; 7: 12. doi: 10.1186/1940-0640-7-12.

30.World Health Organization. Mental Health, Poverty \& Development. Breaking the vicious cycle between mental ill-health and poverty. Geneva: World Health Organization; 2007.

31.World Health Organization. Mental Health and Development. Targeting People with Mental Health Conditions as a Vulnerable Group. Geneva: World Health organization, 2010.

32. Prince M, Patel V, Saxena S, Maj M, Maselko J, Phillips MR, et al. No health without mental health. Lancet. 2007; 370(9590): 859-77.

33. Saraceno B, Barbui C. Poverty and Mental Illness. Can J Psychiatry. 1997; 42(3): 285-90.

34. Lund C, Breen A, Flisher AJ, Kakuma R, Corrigall J, Joska JA, et al. Poverty and common mental disorders in low and middle income countries: a systematic review. Soc Sci Med. 2010; 718(3): 517-28. doi: 10.1016/j.socscimed.2010.04.027.

35. Hudson CG. Socioeconomic Status and Mental Illness: Tests of the Social Causation and Selection Hypotheses. Am J Orthopsychiatry. 2005; 75(1): 3-18.

36. Kuruvilla A, Jacob KS. Poverty, social stress \& mental health. Indian J Med Res. 2007; 126(4): 273-8.

37. Weinreb L, Wehler C, Perloff J, Scott R, Hosmer D, Sagor L, et al. Hunger: its impact on children's health and mental health. Pediatrics. 2002; 110 (4): e41. 